Jurnal Abdidas Volume 2 Nomor 3 Tahun 2021 Halaman 538-544

JURNAL ABDIDAS
http://abdidas.org/index.php/abdidas

JURNAL ABDIDAS
http://abdidas.org/index.php/abdidas

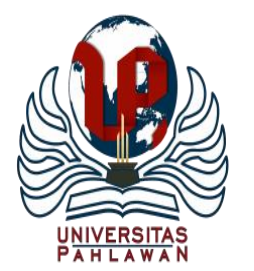

\title{
Pemberdayaan Masyarakat Hulu Melalui Konservasi Sumber Daya Alam sebagai Antisipasi Bencana Kekeringan dan Banjir Sepanjang Tahun di Kabupaten Jember
}

\author{
Idah Andriyani $^{1 \bowtie}$, Sri Wahyuningsih ${ }^{2}$, Mohammad Hoesain $^{3}$, Fariz Kustiawan Alfarisy $^{4}$ \\ Teknik Pertanian, Fakultas Teknik Pertanian, Universitas Jember, Indonesia ${ }^{1,2}$ \\ Proteksi Tanaman, Fakultas Pertanian, Universitas Jember, Indonesia ${ }^{3}$ \\ Ilmu Pertanian, Fakultas Pertanian, Universitas Jember, Indonesia ${ }^{4}$ \\ E-mail: idahandriyani@unej.ac.id ${ }^{1}, \underline{\text { sriwahyuningsih.ftp@unej.ac.id }{ }^{2}}$, hoesain.faperta@unej.ac.id ${ }^{3}$, \\ farizkustiawan@unej.ac.id ${ }^{4}$
}

\begin{abstract}
Abstrak
Perubahan kondisi hidrologis DAS (Daerah Aliran Sungai) Bedadung, Kabupaten Jember menyebabkan terjadi bencana kekeringan dan banjir bandang sepanjang tahun. Bencana tersebut terjadi karena di wilayah hulu terjadi perubahan tata guna lahan dan penerapan pertanian intensif. Tujuan dari pengabdian kepada masyarakat ini adalah untuk pemberdayaan masyarakat di wilayah hulu dalam rangka konservasi sumber daya alam sebagai bentuk antisipasi bencana. Lokasi kegiatan pengabdian kepada masyarakat terletak di Desa Sucopangepok, Kecamatan Jelbuk, Kabupaten Jember. Metode pelaksanaan terbagi menjadi beberapa kegiatan yaitu (i) pendekatan teknik, dan (ii) pendekatan sosial. Metode pengambilan data dilakukan secara RRA (Rapid Rural Appraisal) dan dianalisis secara LFA (Logical Framework Analysis). Hasil pengabdian ini masyarakat dengan pendekatan teknis didampingi untuk menanam pohon konservasi. Kemudian hasil pendekatan sosial dilakukan FGD (Focus Group Discussion) yang secara bersama mengidentifikasi faktor-faktor terjadinya bencana alam. Kegiatan ini dapat menjadi stimulus dalam meningkatkan peran dan partisipasi masyarakat dalam melestarikan sumber daya alam. Kemudian hasil LFA analisis diperoleh fokus isu dan akar masalah dalam mengidentifikasi terjadinya bencana. Dapat disimpulkan bahwa pemberdayaan masyarakat di wilayah hulu DAS Bedadung dapat menjadi upaya mitigasi dalam mengendalikan kerusakan alam dan bencana yang terjadi sepanjang tahun.
\end{abstract}

Kata kunci: hidrologi, konservasi, lestari, LFA

\begin{abstract}
Changes in the hydrological conditions of the Bedadung Watershed of Jember Regency have caused droughts and flash floods throughout the year. The disaster occurred because there were changes in land use in the upstream area and the application of intensive agriculture. The purpose of this community service is to empower communities in the upstream area in the context of conserving natural resources as a form of disaster anticipation. The location of community service activities was located in Sucopangepok Village, Jelbuk District, Jember Regency. The implementation method was divided into several movements, namely (i) a technical approach and (ii) a social approach. The data collection method was carried out by means of RRA (Rapid Rural Appraisal) and analyzed using LFA (Logical Framework Analysis). The result of this community service with a technical approach was accompanied to plant conservation trees. Then the results of the social approach were carried out by FGD (Focus Group Discussion), which jointly identified the factors of natural disasters. This activity can be a stimulus in increasing the role and participation of the community in preserving natural resources. Then the results of the LFA analysis obtained the focus of the issue and the root of the problem in identifying the occurrence of a disaster. It can be concluded that community empowerment in the upstream area of the Bedadung watershed can be a mitigation effort in controlling natural damage and disasters that occur throughout the year.
\end{abstract}

Keywords: hydrology, conservation, sustainable, LFA

Copyright (c) 2021 Idah Andriyani, Sri Wahyuningsih, Mohammad Hoesain, Fariz Kustiawan Alfarisy $\triangle$ Corresponding author

Address : Jl. Kalimantan No. 37 Sumbersari, 68121, Jember

Email : idahandriyani@unej.ac.id

DOI $\quad$ : https://doi.org/10.31004/abdidas.v2i3.314

ISSN 2721-9224 (Media Cetak)

ISSN 2721- 9216 (Media Online) 
539 Pemberdayaan Masyarakat Hulu Melalui Konservasi Sumber Daya Alam sebagai Antisipasi Bencana Kekeringan dan Banjir Sepanjang Tahun di Kabupaten Jember - Idah Andriyani, Sri Wahyuningsih, Mohammad Hoesain, Fariz Kustiawan Alfarisy

DOI: https://doi.org/10.31004/abdidas.v2i3.314

\section{PENDAHULUAN}

Undang-undang Nomor 5 Tahun 1990 mengkaji tentang konservasi sumber daya alam hayati dan ekosistemnya berdasarkan pemanfaatan yang selaras dan seimbang. Oleh karena itu, pelaksanaan dalam undang-undang tersebut dijalankan dalam rencana strategis dari Direktorat Jendral Konservasi Sumber Daya Alam tahun 2020-2024. Salah satu visi yang diangkat adalah keberlanjutan dari sumber daya hutan dan peningkataan kesejahteraan masyarakat. Berdasarkan pendekatan undang-undang maupun rencana strategis yang diangkat sangat erat kaitannya dengan konservasi sumber daya alam. Konservasi yang dimaksud salah satunya fokus pada penanganan daerah aliran sungai pada beberapa wilayah di Indonesia.

DAS (Daerah Aliran Sungai) Bedadung merupakan DAS terpanjang dan terbesar di Kabupaten Jember. DAS Bedadung sebagai sumber kehidupan untuk wilayah Kabupaten Jember dan sekitarnya. Peruntukan saat ini dalam fungsi DAS adalah terdapat pada fungsi beberapa sektor mulai dari pertanian, domestik rumah tangga, perikanan, serta industri.

DAS Bedadung Jember sepanjang tahun mengalami perubahan kondisi hidrologis yang dinamis. Kondisi yang dimaksud adalah perubahan signifikan yang terjadi adalah terjadinya bencana kekeringan dan banjir bandang sepanjang tahun (AntaraJatim, 2021). Berdasarkan pembagian wilayah kajian pengelolaan DAS, terbagi menjadi tiga bagian yaitu wilayah hulu (konservasi), tengah (urban), dan hilir. Beberapa hasil penelitian pendahuluan di bagian wilayah hulu DAS Bedadung telah teridentifikasi menerapkan pertanian intensif dan memberikan pengaruh terhadap kualitas tanah dan air, serta terjadinya perubahan tata guna lahan (Alfarisy et al., 2020)(Alfarisy et al., 2020b)(Petrina et al., 2021).

Wilayah DAS Bedadung di bagian hulu merupakan wilayah konservasi dan merupakan daerah tangkapan hujan. Terjadinya bencana sepanjang tahun mulai dari kekeringan dan banjir bandang, selain perubahan iklim juga dipengaruhi oleh bagaimana kondisi pertanian di wilayah hulu. Hulu DAS Bedadung terletak di Desa Sucopangepok. Desa Sucopangepok merupakan salah satu desa bagian hulu dari Daerah Aliran Sungai (DAS) Bedadung Jember yang terletak di Kecamatan Jelbuk dan berbatasan langsung dengan pegunungan Argopuro. Desa Sucopangepok menjadi salah satu desa penyangga dari kawasan Pegunungan Argopuro yang menjadi kawasan konservasi hutan lindung. Namun sampai saat ini terjadi perubahan tata guna lahan, sehingga kawasan hutan sebagian berubah menjadi kawasan perladangan dan pertanian. Maka tujuan dari kegiatan pengabdian kepada masyarakat ini adalah mengidentifikasi dan pemberdayaan masyarakat hulu DAS Bedadung sebagai upaya antisipasi kekeringan dan banjir bandang yang sering terjadi sepanjang tahun.

\section{METODE}

Kegiatan pengabdian kepada masyarakat dilakukan di Desa Sucopangepok, Kecamatan Jelbuk, Kabupaten Jember. Target sasaran 
540 Pemberdayaan Masyarakat Hulu Melalui Konservasi Sumber Daya Alam sebagai Antisipasi Bencana Kekeringan dan Banjir Sepanjang Tahun di Kabupaten Jember - Idah Andriyani, Sri Wahyuningsih, Mohammad Hoesain, Fariz Kustiawan Alfarisy

DOI: https://doi.org/10.31004/abdidas.v2i3.314

masyarakat dimulai dari dua dusun yaitu Dusun Pangepok dan Cangkring.

Metode pelaksanaan dalam kegiatan ini adalah terdiri dari dua pendekatan yaitu pendekatan teknis dan pendekatan sosial. Kedua pendekatan tersebut telah memenuhi syarat minimal dalam upaya mengelola sumber daya alam berkelanjutan (Renggi et al., 2015). Pendekatan teknis yang dimaksud adalah melakukan pendampingan kegiatan tanam pohon konservasi di sekitar ladang petani. Sedangkan untuk pendekatan sosial dilakukan dengan FGD (Focus Group Discussion) sebagai motivasi dan peningkatan sumber daya manusia.

Pada tahapan monitoring dan evaluasi tim pelaksana pengabdi melakukan sebuah survei menggunakan kuesioner terhadap bagaimana tingkat kepekaan terhadap bencana yang sepanjang tahun terjadi dan mengidentifikasi bersama faktorfaktor yang menyebabkan terjadinya bencana. Pengambilan data dilakukan secara RRA (Rapid Rural Appraisal). Data yang diperoleh akan dianalisis secara deskriptif kualitatif dengan LFA (Logical Framework Analysis). Untuk mengetahui keterkaitan faktor satu dengan yang lain digunakan teknik justifikasi expert.

\section{HASIL DAN PEMBAHASAN}

Kegiatan pertama pengabdian adalah survei pada beberapa titik lokasi pada lahan petani. Wilayah hulu seyogyanya merupakan kondisi dengan didominasi oleh pohon-pohon konservasi. Namun, kondisi nyata bahwa di bagian hulu didonimasi oleh tanaman semusim seperti sengon, pangan maupun hortikultura. Oleh sebab itu, pada Gambar 1 menunjukkan kondisi gersang dan sungai yang kering. Pada gambar 1 bagian (b) menggambarkan terjadinya longsor akibat tanah yang tidak mampu tertahan oleh air.

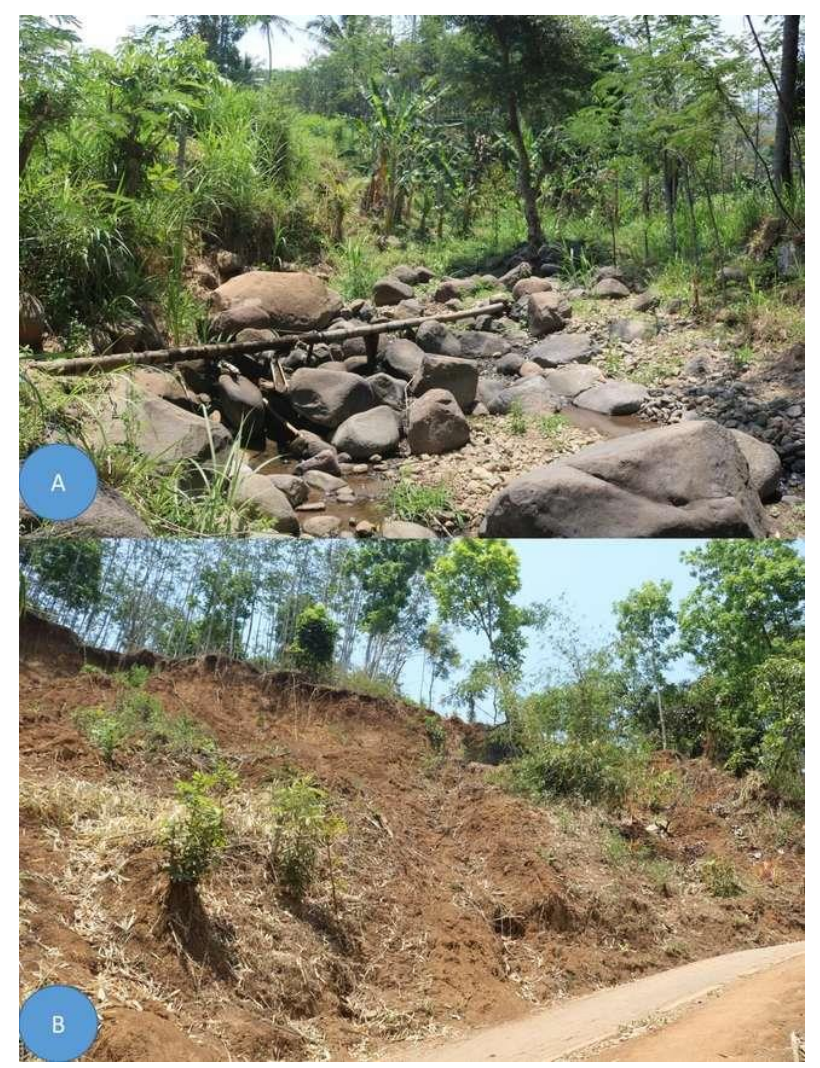

Gambar 1. Kondisi Terkini Saat Tim Pengabdian Survei dalam Kondisi Kering.

Mengatasi bencana seperti yang ditunjukkan pada gambar 1, sebaiknya dilakukan upaya konservasi. Pendekatan teknis dalam upaya konservasi adalah dengan upaya tanam pohon. Pendekatan dengan menggunakan vegetasi mampu mengurangi terjadinya erosi. Tentunya penggunaan tanaman vegetasi yang dipilih harus memiliki karakteristik yang mampu menahan air agar tidak mudah terbawa (Rumaisha et al., 2013.) 
541 Pemberdayaan Masyarakat Hulu Melalui Konservasi Sumber Daya Alam sebagai Antisipasi Bencana Kekeringan dan Banjir Sepanjang Tahun di Kabupaten Jember - Idah Andriyani, Sri Wahyuningsih, Mohammad Hoesain, Fariz Kustiawan Alfarisy

DOI: https://doi.org/10.31004/abdidas.v2i3.314

(Subagyono et al., 2003). Terjadinya erosi yang tidak terkendali maka akan menyebabkan longsor dan perubahan kualitas tanah (Andriyani et al., 2020)(Andriyani et al., 2016). Sebagai contoh bahwa dalam upaya konservasi menggunakan vegetasi bisa dengan soil bioengineering seperti akar rumput Vetiver sp. (Noor et al., 2011).

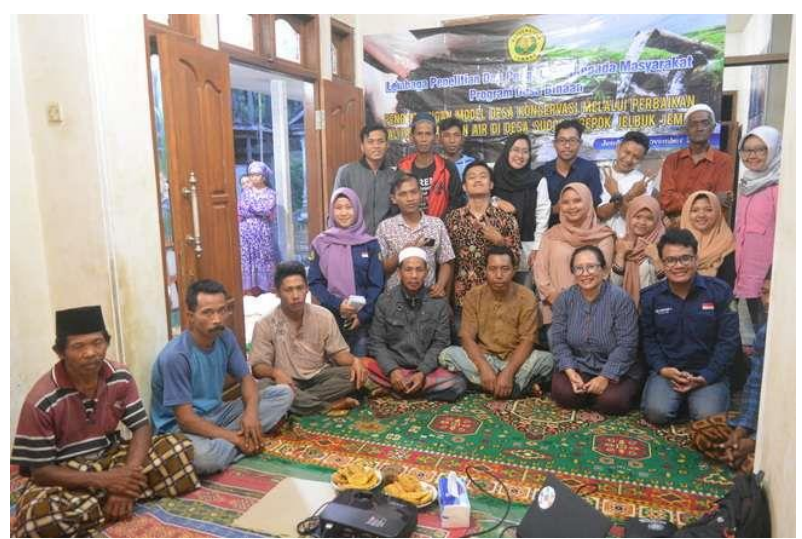

Gambar 2. Kegiatan FGD dalam Rangka Pengelolaan Sumber Daya Alam di Wilayah Hulu DAS Bedadung

Berdasarkan hasil FGD pada gambar 2, maka diperlukan upaya dalam memaksimalkan pengelolaan sumber daya alam yang berkelanjutan, salah satunya melakukan kegiatan konservasi sebagai upaya perbaikan kualitas tanah dan air. Kegiatan FGD merupakan stimulus dalam meningkatkan peran partisipasi masyarakat dalam pelestarian sumber daya alam (Lestari et al., 2014)(Setyowati dan Nugroho, 2015). Beberapa faktor yang mempengaruhi kerusakan sumber daya alam disajikan pada gambar 3. Identifikasi kendala atau hambatan diperoleh dengan cara RRA (Rapid Rural Appraisal) dengan melakukan enumerasi kepada petani secara random sampling. Hasil identifikasi faktor-faktor yang menyebabkan kerusakan sumber daya alam akan dianalisis dengan LFA (Logical Framework Analysis) dengan mengetahui hubungan sebab akibat secara komprehensif di antara beberapa faktor yang berkaitan (dapat dilihat pada tabel 1). Pada bagian ini merupakan bagian dalam upaya pendekatan sosial untuk memperkuat motivasi masyarakat dalam melestarikan alam (Purwanto, 2015).

Tabel 1. Hubungan Sebab Akibat Faktor Kerusakan Sumber Daya Alam dengan LFA.

\begin{tabular}{|c|c|c|c|}
\hline $\begin{array}{c}\text { Faktor-faktor } \\
\text { Kerusakan } \\
\text { Sumber Daya } \\
\text { Alam }\end{array}$ & $\begin{array}{c}\text { Jumlah } \\
\text { In } \\
(\downarrow)\end{array}$ & $\begin{array}{c}\text { Jumlah } \\
\text { Out } \\
(\uparrow)\end{array}$ & Keterangan \\
\hline $\begin{array}{l}\text { Peran Dinas } \\
\text { Pertanian } \\
\text { (Penyuluh) }\end{array}$ & 0 & $3(* *)$ & $\begin{array}{c}\text { Akar } \\
\text { masalah }\end{array}$ \\
\hline $\begin{array}{l}\text { Perilaku dan } \\
\text { wawasan } \\
\text { petani }\end{array}$ & 2 & 2 & \\
\hline $\begin{array}{l}\text { Perbuahan tata } \\
\text { guna lahan }\end{array}$ & 2 & 0 & \\
\hline $\begin{array}{l}\text { Pola tanam } \\
\text { homogen }\end{array}$ & 2 & 1 & \\
\hline $\begin{array}{l}\text { Tidak ada } \\
\text { tanaman } \\
\text { konservasi }\end{array}$ & $3(*)$ & 0 & Fokus isu \\
\hline $\begin{array}{l}\text { Jumlah } \\
\text { penduduk } \\
\text { meningkat }\end{array}$ & 0 & 1 & \\
\hline $\begin{array}{l}\text { Kebutuhan } \\
\text { pangan } \\
\text { meningkat }\end{array}$ & 1 & 0 & \\
\hline $\begin{array}{l}\text { Penggunaan } \\
\text { pupuk dan } \\
\text { pestisida } \\
\text { secara intensif }\end{array}$ & 2 & 0 & \\
\hline $\begin{array}{l}\text { Tidak } \\
\text { memiliki } \\
\text { kelembagaan } \\
\text { tani }\end{array}$ & 2 & 2 & \\
\hline
\end{tabular}


542 Pemberdayaan Masyarakat Hulu Melalui Konservasi Sumber Daya Alam sebagai Antisipasi Bencana Kekeringan dan Banjir Sepanjang Tahun di Kabupaten Jember - Idah Andriyani, Sri Wahyuningsih, Mohammad Hoesain, Fariz Kustiawan Alfarisy

DOI: https://doi.org/10.31004/abdidas.v2i3.314

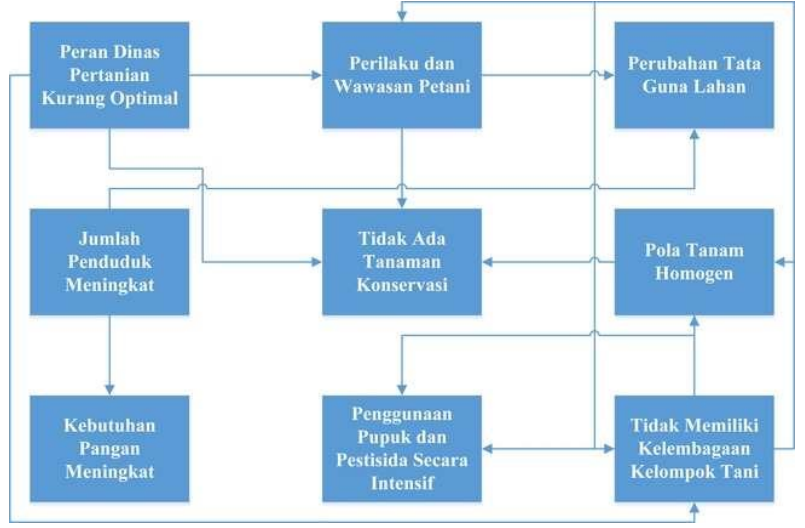

Gambar 3. Hasil Analisis LFA Faktor-faktor Kerusakan Sumber Daya Alam.

Hasil analisis LFA pada tabel 1 diperoleh fokus isu dan akar masalah dari penyebab terjadinya kerusakan sumber daya alam. Akar masalah dari adanya kerusakan sumber daya alam adalah kurangnya peran pemerintah yaitu Dinas Pertanian untuk memberikan penyuluhan terkait sistem budidaya dengan tipologi daerah konservasi. Kurangnya kontribusi peran dinas terkait dan tidak adanya kelembagaan tani, maka mempengaruhi perilaku petani dalam kerusakan sumber daya alam. Fokus isu yang menjadi perhatian adalah tidak adanya tanaman konservasi di desa. Berdasarkan rumusan masalah tersebut adanya program pengembangan desa binaan. Ada beberapa hal yang perlu dilakukan untuk memulihkan kembali sumber daya alam yaitu identifikasi tipologi dan karakterisasi lahan, introduksi tanaman konservasi berbasis agroforestri sebagai upaya mitigasi, serta dan penguatan kelembagaan tani di Desa Sucopangepok.

Ketercapaian program bisa terukur dari perubahan perilaku petani dengan mengubah arah tanam pohon dengan pohon konservasi. Kemudian memahami prinsip konservasi berbasis agroforestri sebagai upaya pendekatan keseimbangan antara bidang pertanian dan kehutanan. Melalui kesempatan diskusi FGD sangat membantu membuka wawasan petani yang semula belum menguasai kaidah dari konservasi sumber daya alam. Berdasarkan dari serangkaian program dan kegiatan yang dilakukan ada beberapa manfaat yang bisa diperoleh terutama masyarakat setempat yaitu:

a. Wawasan meningkat terkait upaya konservasi sebagai mitigasi tanggap bencana;

b. Memahami sistem tanam agroforestri sebagai upaya pengendalian lingkungan berbasis pertanian berkelanjutan;

c. Meningkatkan partisipasi masyarakat dalam upaya tanam pohon;

d. Berkontribusi dalam mewujudkan perbaikan kualitas tanah dan air sebagai implementasi dari kebijakan pemerintah.

\section{SIMPULAN}

Kegiatan pengabdian kepada masyarakat ini melalui program kegiatan konservasi pengelolaan sumber daya alam dapat menstimulus peran partisipasi masyarakat di bagian hulu untuk melestarikan alam sebagai upaya antisipasi menghadapi berbagai bencana yang sering terjadi sepanjang tahun. Kemudian meningkatkan peran serta dan fungsi sosial antara masyarakat dengan stakeholder untuk melakukan tindak lanjut kegiatan konservasi. 
543 Pemberdayaan Masyarakat Hulu Melalui Konservasi Sumber Daya Alam sebagai Antisipasi Bencana Kekeringan dan Banjir Sepanjang Tahun di Kabupaten Jember - Idah Andriyani, Sri Wahyuningsih, Mohammad Hoesain, Fariz Kustiawan Alfarisy

DOI: https://doi.org/10.31004/abdidas.v2i3.314

\section{UCAPAN TERIMAKASIH}

Kegiatan pengabdian masyarakat ini didukung oleh LP2M Universitas Jember melalui dana DIPA Universitas dengan skema Desa Binaan. Kegiatan juga didukung oleh mitra pengabdian yaitu Desa Sucopangepok, Penyuluh Kehutanan, serta dihadiri oleh anggota FORDAS (Forum Daerah Aliran Sungai).

\section{DAFTAR PUSTAKA}

Andriyani, I., Jourdain, D., Lidon, B., Soni, P., \& Kartiwa, B. 2016. Upland Farming System Erosion Yields And Their Constraints To Change For Sustainable Agricultural Conservation Practices: A Case Study Of Land Use And Land Cover ( Lulc ) Change In Indonesia. Land Degradation \& Development. DOI: 10.1002/ldr.2598.

Andriyani, I., Wahyuningsih, S., \& Arumsari, R. S. 2020. Penentuan Tingkat Bahaya Erosi Di Wilayah Das Bedadung Kabupaten Jember. Jurnal Ilmiah Rekayasa Pertanian Dan Biosistem, $\quad 8(1), \quad$ 1-11. https://doi.org/10.29303/jrpb.v8i1.122.

Alfarisy, F. K., I. Andriyani, C. Adibowo. 2020. Evaluation of water quality due to the use of intensive fertilizer on farmer level in the upstream of Bedadung Jember Watershed, East Java, Indonesia. J. Degrade. Min. Land Manage, $\quad 7(4), \quad 2502-2458$. DOI:10.15243/jdmlm.2020.074.2301.

Alfarisy, F. K., I. Andriyani, and C. Adibowo. 2020). Typology of Agricultural Upstream Area of Watershed on Intensive Fertilizer Behaviour on Conservation of Natural Resources in Bedadung Typology of Agricultural Upstream Area of Watershed on Intensive Fertilizer Behaviour on Conservation of Natural Resources in Bedadung. IOP Conf. Series: Earth and Environmental Science 515https://doi.org/10.1088/17551315/515/1/012039.

AntaraJatim. (2021). No Title. Retrieved from
Banjir bandang terjang Desa Bangsalsari Jember website: https://jatim.antaranews.com/berita/448016/b anjir-bandang-terjang-desa-bangsalsarijember.

Lestari, T., Agussabti, M. R. Alibasyah. 2014. Partisipasi Masyarakat Adat dalam Konservasi Sumberdaya Hutan di Kecamatan Kota Jantho Kabupaten Aceh Besar. Jurnal Manajemen Sumberdaya Lahan, 3(2), 506516.

Noor, A., Vahlevi, J., \& Fathurrozi. 2011. Stabilisasi Lereng Untuk Pengendalian Erosi Dengan Soil Bioengineeringmenggunakan Akar Rumput Vetiver. Jurnal POROS TEKNIK, 3(2), 69-74.

Petrina, J. M., F. K. Alfarisy, I. Andriyani, and L. P. Suciati. 2021. The Impacts of Change Forests into Agricultural Land to Social Economic Conditions Society in the Upstream of Bedadung Watershed The Impacts of Change Forests into Agricultural Land to Social Economic Conditions Society in the Upstream of Bedadung Watersh. IOP Conf. Series: Earth and Environmental Science 515. https://doi.org/10.1088/17551315/515/1/012045.

Purwanto. 2015. Meningkatkan Peran Masyarakat Dalam Konservasi: Melalui Penguatan Penata Kelolaan SDA Desa. Direktur Yayasan Tropenbos Indonesia (TBI) dan Operasi Walacea Terpadu. Halaman 103-121.

Renggi, E. R., Indra, M., Muslich, M., \& Asmui. 2015. Panduan Pengelolaan Sumber Daya Hutan dan Pemanfaatan Mekanisme Pembayaran Layanan Ekosistem di Hutan Adat (Guideline for forest resources management and utilization of PES in customary forest). 1-82. Aliansi Masyarakat Adat Nusantara dan Japan Social Development Fund.

Rumaisha, A., H. Tania, dan I. Jamaludin. 2015. eran Vegetasi Terhadap Upaya Pencegahan Erosi Tebing Sub Daerah Aliran Sungai (DAS) Cinambo. Jurusan Agroteknologi, Fakultas Sains dan Teknologi, Universitas Islam Negeri Sunan Gunung Djati Bandung.

Setyowati, D. N., dan S. S. Nugroho. 2015. 
544 Pemberdayaan Masyarakat Hulu Melalui Konservasi Sumber Daya Alam sebagai Antisipasi Bencana Kekeringan dan Banjir Sepanjang Tahun di Kabupaten Jember - Idah Andriyani, Sri Wahyuningsih, Mohammad Hoesain, Fariz Kustiawan Alfarisy

DOI: https://doi.org/10.31004/abdidas.v2i3.314

Penguatan Lembaga Masyarakat Desa Hutan Dalam Rangka Peningkatan Efektivitas Pengelolaan Sumber Daya Hutan Dilereng Gunung Pandan. Sosial, Volume 16 Nomor 2: $42-58$.

Subagyono, K., S. Marwanto, dan U. Kurnia. 2003. Teknik Konservasi Tanah Secara Vegetatif. Bogor: Balai Penelitian Tanah. Pusat Penelitian dan Pengembangan Tanah dan Agroklimat. Badan Penelitian dan Pengembangan Pertanian. Departemen Pertanian. 